\title{
Erratum to: Chest physiotherapy using passive expiratory techniques does not reduce bronchiolitis severity: a randomised controlled trial
}

Isabelle Rochat • Patricia Leis • Marie Bouchardy • Christine Oberli • Hendrika Sourial • Margrit Friedli-Burri • Thomas Perneger •

Constance Barazzone Argiroffo

Published online: 21 October 2011

(C) Springer-Verlag 2011

\section{Erratum to: Eur J Pediatr}

$$
\text { DOI 10.1007/s00431-011-1562-y }
$$

The author wishes to apologize for the missing figure 1 in the original article. Here is the figure and its caption:

The online version of the original article can be found at http:// dx.doi.org/10.1007/s00431-011-1562-y.

I. Rochat $\cdot$ C. Barazzone Argiroffo

Pediatric Pulmonology Unit, Children's Hospital,

University Hospitals,

Geneva, Switzerland

P. Leis $\cdot$ M. Bouchardy $\cdot$ C. Oberli $\cdot$ H. Sourial $\cdot$ M. Friedli-Burri

Pediatric Physiotherapy, Children's Hospital,

University Hospitals,

Geneva, Switzerland

\section{T. Perneger}

Division of Clinical Epidemiology, University Hospitals,

Geneva, Switzerland

\section{Rochat $(\square)$}

Pediatric Pulmonology Unit, CHUV,

Rue du Bugnon 46,

1011 Lausanne, Switzerland

e-mail: isabelle.rochat@chuv.ch

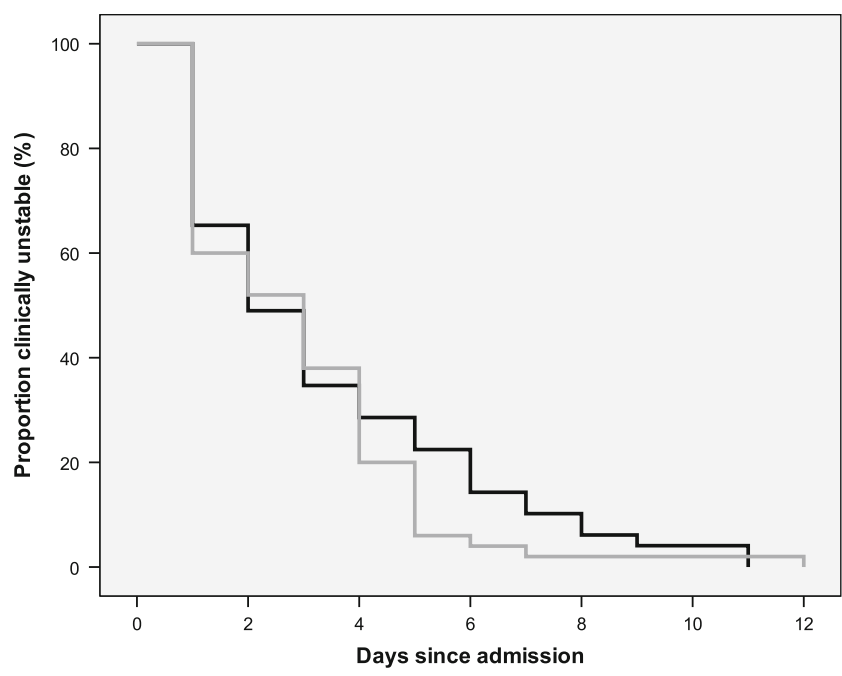

Fig. 1 Comparison of the time to clinical stability in children hospitalised with bronchiolitis randomised to chest physiotherapy (grey line) or control group (black line). The slight difference at day 5 was not significant $(\mathrm{P}=0.35)$ 